\title{
Ability of body mass index to predict abnormal waist circumference: receiving operating characteristics analysis
}

\author{
Márcio Weissheimer Lauria ${ }^{1,2^{*}}$, Lívia Maria Pinheiro Moreira², George Luiz Lins Machado-Coelho3 \\ Raimundo Marques do Nascimento Neto ${ }^{3}$, Maria Marta Sarquis Soares ${ }^{1,2}$ and Adauto Versiani Ramos ${ }^{2}$
}

\begin{abstract}
Background: Body mass index (BMI) and waist circumference (WC) are the most used anthropometric measures to identify obesity. While BMI is considered to be a simple and accurate estimate of general adiposity, WC is an alternative surrogate measure of visceral obesity. However, WC is subject to significant inter-examiner variation. The aim of the present study was to correlate BMI and WC measures in a group of Brazilian adults to determine the most accurate BMI values for predicting abnormal WC.

Methods: BMI and WC were measured in 1184 volunteers (45.6 $\pm 17.3 \mathrm{yrs} ; 69 \%$ female) using standard procedures. Abnormal WC was defined as $\geq 88 \mathrm{~cm}$ in women and $\geq 102 \mathrm{~cm}$ in men using the traditional criteria, and $\geq 80 \mathrm{~cm}$ in women and $\geq 90 \mathrm{~cm}$ in men using the new criteria. Statistical analysis involved the calculation of Pearson's correlation coefficients and receiver operating characteristic (ROC) curves.

Results: BMI was strongly correlated with WC (women: $r=0.87, p<0.0001$, area under ROC curve $=0.93 \pm 0.1$; men: $r=0.89, p<0.0001$, area under ROC curve $=0.94 \pm 0.01$ ). The most accurate BMl cutoff point for abnormal WC was $27.1 \mathrm{~kg} / \mathrm{m}^{2}$ for men and $26.8 \mathrm{~kg} / \mathrm{m}^{2}$ for women using the traditional WC criteria, and $24.7 \mathrm{~kg} / \mathrm{m}^{2}$ for men and $24.9 \mathrm{~kg} / \mathrm{m}^{2}$ for women using the new WC criteria.

Conclusion: Based on the strong correlation found with WC, BMI can be used as the primary anthropometric measure to estimate adiposity, since both obese and most overweight subjects will have abnormal WC.
\end{abstract}

Keywords: Body mass index, Waist circumference, Obesity

\section{Background}

Obesity is the fastest-growing chronic disease in both children and adults, and is becoming a global epidemic. In 2008 , an estimated 1.5 billion adults worldwide were considered to be overweight or obese [1]. This public health concern is the cause of a number of comorbidities, being associated with high health care costs. Obesity is a risk factor for a variety of diseases, such as type 2 diabetes mellitus, cardiovascular disease, hypertension and cancer [2-4].

Overweight in adults is defined as a body mass index (BMI = weight in kilograms/height in meters squared) of 25.0 to $29.9 \mathrm{~kg} / \mathrm{m}^{2}$, while obesity is defined as a BMI $\geq$

\footnotetext{
* Correspondence: marciowlauria@gmail.com

${ }^{1}$ Internal Medicine, School of Medicine, Federal University of Minas Gerais, Belo Horizonte, MG, Brazil

${ }^{2}$ Endocrinology, Felicio Rocho Hospital, Belo Horizonte, MG, Brazil Full list of author information is available at the end of the article
}

$30.0 \mathrm{~kg} / \mathrm{m}^{2}$ [5]. BMI was first described by Adolphus Quetelet in the mid- nineteenth century, based on the observation that body weight is proportional to height squared in adults with normal body frames [6]. BMI is widely employed as an anthropometric estimate of general adiposity.

In recognition that visceral fat accumulation increases the risk of metabolic disease, waist circumference (WC) has been used as an alternative surrogate measure of obesity. Abnormal WC is traditionally defined as $\geq 88 \mathrm{~cm}$ in women and $\geq 102 \mathrm{~cm}$ in men, based on cutoff points advocated by Lean et al. in 1995 [7]. Recently, however, new cutoff points have been proposed for abnormal WC taking into consideration ethnic aspects. In South Americans, abnormal WC is defined as $\geq 80 \mathrm{~cm}$ in women and $\geq 90 \mathrm{~cm}$ in men. These values are based on

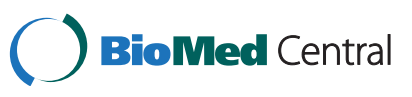

(

(C) 2013 Lauria et al.; licensee BioMed Central Ltd. This is an open access article distributed under the terms of the Creative Commons Attribution License (http://creativecommons.org/licenses/by/2.0), which permits unrestricted use, distribution, and reproduction in any medium, provided the original work is properly cited. 
the definition of metabolic syndrome by the International Diabetes Federation (IDF) [8].

However, while weight and height measurements are relatively simple and accurate, WC is subject to significant inter-examiner variation, which leads to concerns regarding its reliability. Furthermore, BMI has been described as a better predictor of cardiovascular events than WC in some studies [9-11].

The aim of the present study was to correlate BMI and WC in a group of Brazilian adults to determine the most accurate BMI values that best predict abnormal $\mathrm{WC}$ in men and women.

\section{Methods}

A total of 1184 subjects were consecutively evaluated and included in the present study. The volunteers spontaneously presented for a medical appointment at a general endocrine clinic at the Felício Rocho Hospital, Brazil, between March 2011 and February 2012. The exclusion criteria were the following: age $<18$ yrs, history of abdominoplasty, history of solid organ transplant and chronic kidney disease.

All the data were evaluated by physicians trained in measuring weight, height and WC using standard techniques. BMI was obtained from height and weight measurements with the subjects barefoot and wearing light clothing. A scale with accurate weighing up to $150 \mathrm{~kg}$ was used for weight determination. Height was measured to the nearest $1 \mathrm{~cm}$ using a stadiometer. For this measurement, the participants were positioned with heels, buttocks, shoulder blades and back of the head in contact with the backboard of the stadiometer and the top of the head in the Frankfort horizontal plane. BMI was calculated as weight in kilograms divided by height in meters squared $\left(\mathrm{kg} / \mathrm{m}^{2}\right)$.

WC was measured with the subject in the standing position, at the end of exhalation, using a non-elastic measuring tape placed horizontally at the midpoint between the lowest rib and top of the iliac crest, as defined by the World Health Organization. Two different cutoff points were used for establishing abnormal WC: 1) $\geq 88 \mathrm{~cm}$ in women and $\geq 102 \mathrm{~cm}$ in men (traditional criteria); and 2) $\geq 80 \mathrm{~cm}$ in women and $\geq 90 \mathrm{~cm}$ in men (new criteria). The subjects were allocated into two groups (normal and abnormal) based on these two cutoff points.

To estimate the most accurate BMI cutoff point for discriminating normal from abnormal WC, receiving operating characteristic (ROC) curves were constructed and separated by gender using both WC classification criteria. The point closest to the maximum sensitivity and specificity point was selected as the cutoff.

Correlation analyses were performed between the BMI and WC using Pearson's correlation coefficient ( $r$ ) and area under ROC curves with 95\% confidence interval $\{$ AUC $(95 \% \mathrm{CI})\}$. An $r$ value $>0.7$ indicated a strong correlation; $r=0.4$ to 0.7 indicated a moderate correlation, and $r<0.4$ denoted a weak correlation. The Prism 4.0 software (Graph Pad, San Diego, CA, USA) was used for all analyses and a $p$ value $<0.05$ was deemed statistically significant.

\section{Results and discussion}

Mean patient age was $45.6 \pm 17.3$ yrs. Women accounted for $69 \%$ of the sample. Mean BMI was $25.4 \pm 4.8 \mathrm{~kg} / \mathrm{m}^{2}$ for men and $27.1 \pm 5.9 \mathrm{~kg} / \mathrm{m}^{2}$ for women. Mean WC was $89.9 \pm 14.4 \mathrm{~cm}$ for men and $88.9 \pm 15.1 \mathrm{~cm}$ for women.

Pearson's correlation coefficient between BMI and WC was 0.89 for men $(p<0.0001)$ and 0.87 for women $(p<$ 0.0001). The AUC ( $95 \% \mathrm{CI}$ ) between BMI and WC using the traditional classification was 0.94 (0.91-0.96) for men and 0.93 (0.91-0.95) for women (Figure 1). The AUC (95\% CI) between BMI and WC using the new criteria was $0.95(0.92-0.97)$ for men and 0.93 (0.91-0.94) for women (Figure 2).

The most accurate BMI cutoff point for abnormal WC was $27.1 \mathrm{~kg} / \mathrm{m}^{2}$ for men (sensitivity: 96\%; specificity: $81 \%$ ) and $26.8 \mathrm{~kg} / \mathrm{m}^{2}$ for women (sensitivity: $82 \%$; specificity: $89 \%$ ) using the traditional classification (Figure 1). Using the new criteria, the most accurate BMI cutoff point for abnormal WC was $24.7 \mathrm{~kg} / \mathrm{m}^{2}$ for men (sensitivity: $92 \%$; specificity: $84 \%$ ) and $24.9 \mathrm{~kg} / \mathrm{m}^{2}$ for women (sensitivity: $82 \%$; specificity: 91\%) (Figure 2).

The present cross-sectional study with $>1000$ subjects demonstrated a strong correlation between BMI and WC in both genders. This study involved patients at ages ranging from 18 to 90 yrs. Moreover, no distinctions were made regarding ethnicity. In fact, considering the ethnic mix of the Brazilian population, the present findings may also apply to other populations. Strong correlation between BMI and WC (80-85\%) has also been described in large cohorts $[9,10]$. Therefore, BMI provides a good estimation of $\mathrm{WC}$ in the majority of patients and can reasonably replace it, which is a very convenient feature in clinical practice.

BMI is the most widely employed anthropometric measure, due in part to its convenience, safety and minimal cost. Several studies have related BMI to mortality and morbidity rates, thereby demonstrating that subjects with normal BMI or slightly overweight are in the lower risk group [12]. A recent meta-analysis found that obesity class 2 and $3\left(B M I=35-39.9\right.$ and $\geq 40 \mathrm{~kg} / \mathrm{m}^{2}$, respectively) were significantly associated with increased overall mortality, while class 1 obesity (BMI $=30-$ $34.9 \mathrm{~kg} / \mathrm{m}^{2}$ ) was not associated with higher mortality rates and overweight was actually associated with significantly lower overall mortality rates [13].

On the other hand, using BMI alone for obesity assessment could be a limitation because it reflects both fat 

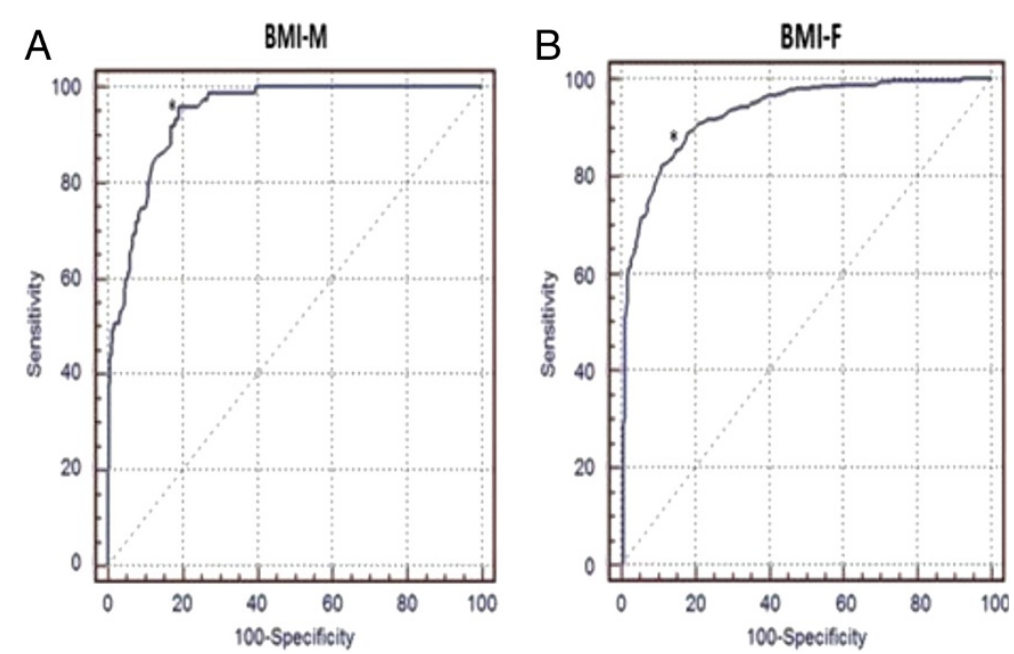

Figure 1 ROC curve for prediction of central obesity (WC $=102 \mathrm{~cm}$ in men and $88 \mathrm{~cm}$ in women). (A) for men: cut-off value $=27.1 \mathrm{~kg} / \mathrm{m}^{2}$ \{sensitivity: $96 \%$; specificity: $81 \%$, AUC (95\% Cl) $=0.94(0.91-0.96)\}$ (B) for women: cut-off value $=26.8 \mathrm{~kg} / \mathrm{m}^{2}$ \{sensitivity: $82 \%$; specificity: $89 \%$, AUC $(95 \% \mathrm{Cl})=0.93(0.91-0.95)\} \mathrm{AUC}(95 \% \mathrm{Cl})=$ area under ROC curves with 95\% confidence interval; BMI-F = Body mass index in men, BMI-M = Body mass index in men.

and lean mass and does not discriminate fat distribution [14]. Okorududu et al. conducted a systematic review of studies evaluating the performance of BMI in the detection of body adiposity and found that cutoff points for the diagnosis of obesity have high specificity but low sensitivity regarding the identification of adiposity, as half of the individuals with a high percentage of fat were not identified using this measure [15]. Moreover, BMI is particularly inaccurate in subjects with elevated lean body mass, such as athletes, and cannot be generalized among different ethnic groups. This measure is also criticized because it makes no difference between men and women [16].
WC, in turn, provides an estimation of abdominal fat and has been related to insulin resistance and cardiovascular risk. It is the cornerstone of the IDF definition of metabolic syndrome [8]. However, WC measurement is frequently unreliable, since it varies depending on the precise site at which the measurement is performed [17,18]. A study published in 2008 determined excellent inter-observer reliability for weight, height and derived BMI $(r>0.99)$, but unsatisfactory reliability for WC $(r=0.92)$. Only $1 \%$ of volunteers were misclassified as overweight or obese based on the BMI, whereas the use of WC led to misclassification in $6 \%$ of cases [19].
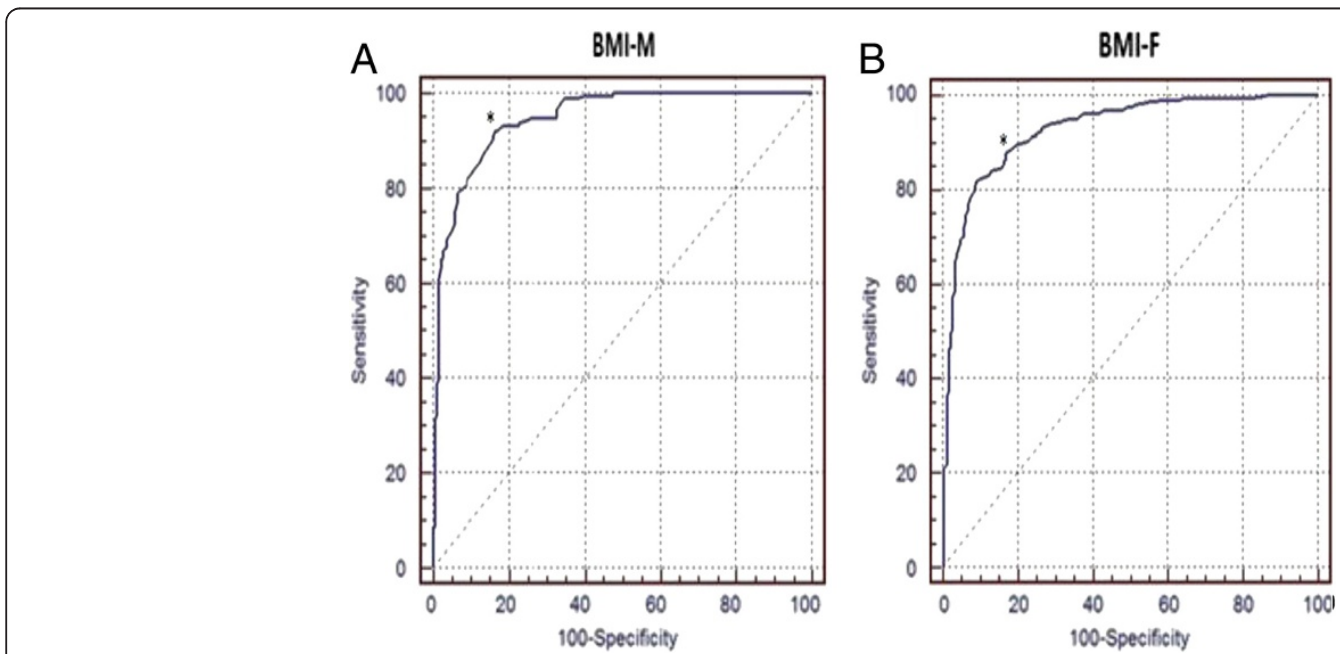

Figure 2 ROC curve for prediction of central obesity (WC $=90 \mathrm{~cm}$ in men and $80 \mathrm{~cm}$ in women). (A) for men: cut-off value $=24.7 \mathrm{~kg} / \mathrm{m}^{2}$ for men \{sensitivity: 92\%; specificity: 84\%, AUC $(95 \% \mathrm{Cl})=0.95(0.92-0.97)\}$. (B) for women: cut-off value = $24.9 \mathrm{~kg} / \mathrm{m} 2$ for women $\{$ sensitivity: $82 \%$; specificity: $91 \%$, AUC $(95 \% \mathrm{Cl})=0.93(0.91-0.94)\}$. AUC $(95 \% \mathrm{Cl})=$ area under ROC curves with $95 \%$ confidence interval; BMI-F $=$ Body mass index in men, BMI-M = Body mass index in men. 
Moreover, WC is equal or inferior to $\mathrm{BMI}$ in predicting mortality or cardiovascular disease, according to recent data from large cohorts [9-11]. These results challenge current recommendations on obesity-related cardiovascular risk management based on WC and underscore the need for further research to improve the reliability of anthropometric measurements by physicians.

In 2006, IDF recommended modifications in the definition of abnormal WC, taking into account ethnic aspects [8]. In the present study, the impact of these modifications in the relation between WC and BMI was demonstrated. Using the traditional criteria, BMI above $27 \mathrm{~kg} / \mathrm{m}^{2}$ was the most accurate cutoff point for the prediction of abnormal WC in both genders. Interestingly, the use of the new and more stringent criteria determined that all overweight/obese subjects had abnormal WC and the most accurate cutoff point was approximately $25 \mathrm{~kg} / \mathrm{m}^{2}$ in both men and women. This represents a controversial issue since overweight has been associated with significantly lower mortality overall relative to the normal weight category [13].

\section{Conclusions}

Based on the present findings of strong correlation with WC, BMI can reasonably be used as the first anthropometric measure to estimate adiposity since obese and the majority overweight subjects will have abnormal WC. For these patients, WC measure can be waived. For patients with a lower BMI, WC remains informative and has yet to be determined.

\section{Abbreviations \\ AUC (95\% Cl): Area under ROC Curves with 95\% confidence interval; BMl: Body mass index; IDF: International diabetes federation; R: Pearson's correlation coefficient; ROC: Receiving operating characteristics; WC: Waist circumference.}

\section{Competing interests}

The authors have no conflicts of interest and this study was not supported by any pharmaceutical company.

\section{Authors' contributions}

MWL 1) have made substantial contributions to conception and design, or acquisition of data, or analysis and interpretation of data; 2) have been involved in drafting the manuscript or revising it critically for important intellectual content; LMPM 1) have made substantial contributions to conception and design, or acquisition of data, or analysis and interpretation of data; 2) have been involved in drafting the manuscript or revising it critically for important intellectual content; GLLM-C 1) have made substantial contributions to conception and design, or acquisition of data, or analysis and interpretation of data; RMdoNN 1) have made substantial contributions to conception and design, or acquisition of data, or analysis and interpretation of data; MMSS Have given final approval of the version to be published. AVR Have given final approval of the version to be published. All authors read and approved the final manuscript.

\section{Author details}

${ }^{1}$ Internal Medicine, School of Medicine, Federal University of Minas Gerais, Belo Horizonte, MG, Brazil. Endocrinology, Felicio Rocho Hospital, Belo Horizonte, MG, Brazil. ${ }^{3}$ Medical Science, School of Medicine, Federal University of Ouro Preto, Ouro Preto, MG, Brazil.
Received: 28 May 2013 Accepted: 9 November 2013

Published: 19 November 2013

\section{References}

1. Finucane MM, Stevens GA, Cowan MJ, Danaei G, Lin JK, Paciorek CJ, et al: National, regional, and global trends in body-mass index since 1980: systematic analysis of health examination surveys and epidemiological studies with 960 country-years and 9.1 million participants. Lancet 2011, 377(9765):557-567.

2. Wilson PW, D'Agostino RB, Sullivan L, Parise $H$, Kannel WB: Overweight and obesity as determinants of cardiovascular risk: the Framingham experience. Arch Intern Med 2002, 162:1867-1872.

3. Colditz GA, Willett WC, Rotnitzky A, Manson JE: Weight gain as a risk factor for clinical diabetes mellitus in women. Ann Intern Med 1995, 122:481-486.

4. Calle EE, Rodriguez C, Walker-Thurmond K, Thun MJ: Overweight, obesity, and mortality from cancer in a prospectively studied cohort of U.S. adults. N Engl J Med 2003, 348:1625-1638.

5. World Health Organization: Obesity: preventing and managing the global epidemic. Report of a WHO consultation. World Health Organ Tech Rep Ser 2000, 894:1-253. i-xii.

6. Quetelet A: A treatise on man and the development of his faculties 1842. Obes Res 1994, 2(1):72-85.

7. Lean ME, Han TS, Morrison CE: Waist circumference as a measure for indicating need for weight management. BMJ 1995, 311:158-161.

8. International Diabetes Federation: The IDF consensus worldwide definition of the metabolic syndrome. Available from: http://www.idf.org/webdata/docs/ IDF_Meta_def_final.pdf.

9. Whitlock G, Lewington S, Sherliker P, Clarke R, Emberson J, et al: Body-mass index and cause-specific mortality in 900000 adults: collaborative analyses of 57 prospective studies. Lancet 2009, 373(9669):1083-1096.

10. Pischon T, Boeing H, Hoffmann K, Bergmann M, Schulze MB, et al: General and abdominal adiposity and risk of death in Europe. N Engl J Med 2008, 359(20):2105-2120.

11. Wormser D, Kaptoge S, Di Angelantonio E, Wood AM, Pennells L, Thompson A, et al: Separate and combined associations of body-mass index and abdominal adiposity with cardiovascular disease: collaborative analysis of 58 prospective studies. Lancet 2011, 377(9771):1085-1095.

12. Taylor AE, Ben-Shlomo SE, Martin RM, Whincup PH, Yarnell JW, Wannamethee SG, et al: Comparison of the associations of body mass index and measures of central adiposity and fat mass with coronary heart disease, diabetes, and all-cause mortality: a study using data from 4 UK cohorts. Am J Clin Nutr 2010, 91:547-556.

13. Flegal KM, Kit BK, Orpana H, Graubard BI: Association of all-cause mortality with overweight and obesity using standard body mass index categories: a systematic review and meta-analysis. JAMA 2013, 309(1):71-82.

14. Ferket BS, Colkesen EB, Visser JJ, et al: Systematic review of guidelines on cardiovascular risk assessment which recommendations should clinicians follow for a cardiovascular health check? Arch Intern Med 2010, 170:27-40.

15. Okorodudu DO, Jumean MF, Montori VM, Romero-Corral A, Somers VK, Erwin PJ, et al: Diagnostic performance of body mass index to identify obesity as defined by body adiposity: a systematic review and meta-analysis. Int $J$ Obes 2010, 34:791-799.

16. van Dijk SB, Takken T, Prinsen EC, Wittink H: Different anthropometric adiposity measures and their association with cardiovascular disease risk factors: a meta-analysis. Neth Heart J 2012, 20:208-218.

17. Klein S, Allison DB, Heymsfield SB, Kelley DE, Leibel RL, Nonas C, et al: Waist circumference and cardiometabolic risk: a consensus statement from shaping america"s health: association for weight management and obesity prevention; NAASO, the obesity society; the american society for nutrition; and the american diabetes association. Diab Care 2007, 30(6):1647-1652.

18. Vazquez G, Duval S, Jacobs DR Jr, Silventoinen K: Comparison of body mass index, waist circumference, and waist/hip ratio in predicting incident diabetes: a meta-analysis. Epidemiol Rev 2007, 29:115-128.

19. Sebo P, Beer-Borst S, Haller DM, Bovier PA: Reliability of doctors' anthropometric measurements to detect obesity. Prev Med 2008, 47(4):389-393.

doi:10.1186/1758-5996-5-74

Cite this article as: Lauria et al:: Ability of body mass index to predict abnormal waist circumference: receiving operating characteristics analysis. Diabetology \& Metabolic Syndrome 2013 5:74. 